\title{
Tricuspid Valve Endocarditis Following Septic Abortion
}

\author{
Bimal K. Agrawal ${ }^{1}$, Neha Vashishat ${ }^{2}$, Barinder Kaur ${ }^{3}$, Gaurav Aggarwal ${ }^{4}$
}

${ }^{1}$ Department of Medicine, M. M. Institute of Medical Sciences and Research, Maharishi Markandeshwar (Deemed to be University), Mullana, Haryana, India. ²Department of Obstetrics and Gynaecology, M. M. Institute of Medical Sciences and Research, Maharishi Markandeshwar (Deemed to be University), Mullana, Haryana, India. ${ }^{3}$ Department of Medicine, M. M. Institute of Medical Sciences and Research, Maharishi Markandeshwar

(Deemed to be University), Mullana, Haryana, India. ${ }^{4}$ Department of Cardiology, M. M. Institute of Medical

Sciences and Research, Maharishi Markandeshwar (Deemed to be University), Mullana, Haryana, India.

\section{INTRODUCTION}

In patients of infective endocarditis, aortic valve is most commonly involved followed by the mitral valve. Pulmonary and tricuspid valves are the least involved valves. Multiple valves can also be involved and are seen in $17-22 \%$ cases.[1] Right sided infective endocarditis is seen in approximately $10 \%$ of the total cases. ${ }^{[2]}$ Isolated tricuspid valve prevalence has been reported in the range of $2.5-3.1 \%$ and isolated pulmonary valve involvement has been reported to be $2 \%{ }^{[3,4]}$ Tricuspid valve (TV) endocarditis commonly occurs in intravenous drug users (IVDU) or any abnormality of the TV. The other causes could be, patients with implantable cardiac defibrillators (ICD), central venous catheter or right sided cardiac anomalies.[5] We report a case of a previously healthy young woman, who was neither an intravenous (IV) drug user nor had any congenital heart disease, who developed TV endocarditis after an induced abortion. This case exemplifies the need for strong suspicion for right-sided IE in patients presenting with pyrexia of unknown origin (PUO) or cardiorespiratory symptoms after gynaecological interventions.

\section{PRESENTATION OF CASE}

A 27 yeas female reported to outpatient department with history of fever, breathlessness and cough of about three-week duration. The patient had approached a local unqualified health worker for termination of her pregnancy of eight weeks. Few days after the procedure the patient started having fever. The fever was initially low grade associated with anorexia, malaise, weakness. Subsequently the intensity of fever increased to 102-104 of followed by chest discomfort, cough and breathlessness grade II. She did not give any history of purulent expectoration, yellowish discoloration of eyes and urine, arthritis, photosensitivity, oral ulcer, sore throat or burning micturition.
Corresponding Author: Dr. Bimal K. Agrawal, Principal,

M. M. Institute of Medical Sciences and Research, Maharishi Markandeshwar (Deemed to be University), Mullana-133207, Haryana, India. E-mail:onlybimal@gmail.com

DOI: $10.14260 /$ jemds/2020/25

Financial or Other Competing Interests: None.

How to Cite This Article:

Agrawal BK, Vashishat N, Kaur B, et al. Tricuspid valve endocarditis following septic abortion. J. Evolution Med. Dent. Sci. 2020;9(02):116-117, DOI: $10.14260 /$ jemds/2020/25

Submission 18-11-2019,

Peer Review 26-12-2019,

Acceptance 03-01-2020,

Published 13-01-2020. 
On examination she was ill and having toxic look. She was looking pale and jugular venous pressure was raised $3 \mathrm{~cm}$ above clavicle. Her pulse rate was 128 beats/min regular with blood pressure of $122 / 70 \mathrm{mmHg}$ and respiratory rate of $26 / \mathrm{min}$. There was no jaundice, clubbing. Her respiratory examination showed diminished breath sound over both bases and crepitations over the bilateral lung fields. The cardiovascular examination showed systolic murmur in the tricuspid area. Abdominal examination revealed tender hepatomegaly $2 \mathrm{~cm}$ below right costal margins. Gynaecologically, bimanual examination revealed uterus 6 weeks size, cervical motion tenderness present. Investigation showed haemoglobin of $5.9 \mathrm{gm} \%$, total leucocyte count of $20,100 /$ cumm which increased to 31,000 /cumm with ESR of $129 \mathrm{~mm}$ in $1^{\text {st }}$ hour. Renal function tests and liver function test were normal. Arterial blood gas analysis showed lactic acidosis with hypoxemia. The chest xray showed midzone and lower one pulmonary infiltrates with cavitation and bilateral pleural effusion (Figure 1, 2). The electro cardiography showed sinus tachycardia. The pleural fluid samples sent for analysis showed 200 cells/cumm with lymphocyte predominance, glucose of $107 \mathrm{mg} / \mathrm{dl}$ and protein of $2.9 \mathrm{gm} / \mathrm{dl}$ and adenosine deaminase of $22 \mathrm{U} / \mathrm{L}$. On ultrasonography retained products of conception was seen for which dilation and evacuation was done. The working diagnosis was incomplete abortion with septicaemia. The echocardiography revealed tricuspid valve vegetation (septal leaflet)(Figure 3) with moderate tricuspid regurgitation. In view of the right sided infective endocarditis the chest findings were correlated to be septic emboli. Three sets of blood cultures sent were sterile with no growth seen. The patient was treated with parenteral ceftriaxone and gentamycin for four weeks. The general condition of the patient gradually improved, however it took nearly three weeks for the fever and tachycardia to settle down. The patient was discharged in stable condition after a month's stay in hospital. The echocardiography repeated on a follow-up visit did not show any vegetation.

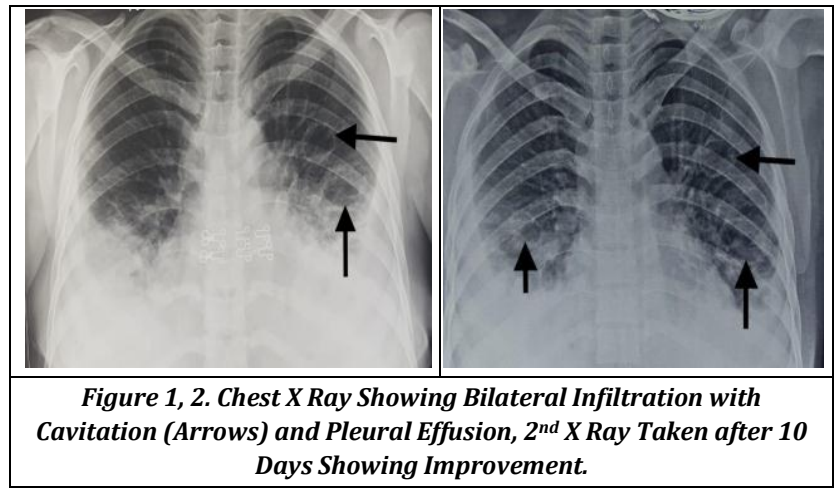

\section{DISCUSSION}

In pregnancy, endocarditis can be precipitated by urinary tract infections, perinatal infections, or septic thrombophlebitis of pelvic vein. Pelvic infection occurring secondary to septic abortions can also provide an entry portal for bacterial infections. Tricuspid valve involvement in our patient was due to the transmission of infection through pelvic veins into venous system, and right sided valves being on the venous side of the heart are more prone to it. Staphylococci, streptococci and very occasionally bacteroides and gram-negative bacilli are the causative organisms.[6-7] However our patient had culture negative endocarditis, which was probably because of antibiotics she had received before arriving to our hospital. History, clinical examination and high-suspicion index remain the cornerstones of diagnosis. Although typical Duke criteria do not distinguish between left sided infective endocarditis (LSIE) and right sided infective endocarditis (RSIE), diagnosis can be dramatically delayed as many signs associated with LSIE are usually absent in RSIE like peripheral systemic embolization including splinter haemorrhages, whereas in RSIE septic/pulmonary embolism picture dominate. Therefore patients presenting with prolonged fever, pleuritic pain, cough, tachycardia, and multiple pulmonary infiltrates should raise a clinical suspicion of right sided endocarditis. We conclude that right sided infective endocarditis should be kept as one of the differential diagnosis in patients presenting with fever, cough, breathlessness and diffuse pulmonary infiltrates on chest x-ray and with a history of abortion and some gynaecological intervention done.

\section{REFERENCES}

[1] Fayad G, Leroy G, Devos P, et al. Characteristics and prognosis of patients requiring valve surgery during active infective endocarditis. J Heart Valve Dis 2011;20(2):223-8.

[2] Hussey HH, Katz S. Infections resulting from narcotic addiction: Report of 102 cases. Am J Med 1950;9(2):18693.

[3] Heydari AA, Safari H, Sarvghad MR. Isolated tricuspid valve endocarditis. Int J Infect Dis 2009;13(3):e109-e11.

[4] Ramadan FB, Beanlands DS, Burwash IG. Isolated pulmonic valve endocarditis in healthy hearts: a case report and review of the literature. Can J Cardiol 2000;16(10):1282-8.

[5] Brusch JL. Infective endocarditis and its mimics in the critical care unit. In: Cunha BA, edr. Infectious diseases in critical care. $2^{\text {nd }}$ edn. New York, NY: Informa Healthcare 2007: p. 261-2.

[6] Akram M, Khan IA. Isolated pulmonic valve endocarditis caused by group B streprococcus (Streptococcus agalactiae) - a case report and literature review. Angiology 2001;52(3):211-5.

[7] Kebed KY, Bishu K, Al Adham RI, et al. Pregnancy and postpartum infective endocarditis: a systematic review. Mayo Clin Proc 2014;89(8):1143-52. 